\title{
Lei de responsabilidade fiscal e Lei de acesso à informação: uma análise do nível de transparência dos municípios do estado de Rondônia
}

\author{
Leon Nascimento Duarte ${ }^{1}$ \\ Geany Cleide Carvalho Martins ${ }^{2}$ \\ João Paulo Borges de Loureiro ${ }^{3}$ \\ Marcos Antônio Souza dos Santos ${ }^{4}$
}

\begin{abstract}
RESUMO
A Lei de Responsabilidade Fiscal (LRF) e a Lei de Acesso à Informação (LAI) visam melhorar a gestão e prestação de contas dos recursos públicos, bem como dar maior transparência para a sociedade. Para conhecer o nível de transparência dos municípios rondonienses em relação a LRF e a LAI, foram analisados os portais da transparência dos 52 municípios do Estado, utilizando o índice de conformidade como parâmetro para avaliar o grau de adesão as referidas normas. Foram analisados 30 indicadores de conformidade, 15 relacionados à LRF e 15 à LAI. Assim, o estudo examinou a frequência de divulgação e se houve influência por características como a mesorregião ou população. Os resultados revelam que as prefeituras rondonienses tiveram um alto nível de aderência aos índices de conformidade para LRF e LAI. O menor nível de transparência foi observado na região de Porto Velho, com IC Geral Médio de 94\%. Já o maior número de informações disponibilizadas ocorreu na região de Jaru, que obteve IC Geral Médio de 97,33\%. Mesmo em municípios menos populosos, foram encontrados níveis de conformidade com cumprimento integral, ou seja, a transparência, não está diretamente ligada a quantidade de pessoas vivendo em uma localidade ou sua capacidade econômica, e sim ao compromisso em atender a obrigação de divulgar informações públicas.
\end{abstract}

Palavras chave: Transparência; Gestão pública; Responsabilidade fiscal; Acesso à informação.

\section{Fiscal responsibility law and access to information law: an analysis of the level of transparency of municipalities in the state of Rondonia}

\begin{abstract}
The Fiscal Responsibility Act (LRF) and the Access to Information Act (LAI) aim to improve the management and accountability of public resources, as well as to provide greater transparency for society. In order to know the level of transparency of the municipalities in relation to the LRF and the LAI, the transparency portals of the 52 municipalities in the State were analysed, using the compliance index as a parameter to assess the degree of adherence to these standards. Thirty compliance indicators were analysed, 15 related to the LRF and 15 to the LAI. Thus, the study examined the frequency of dissemination and whether there was influence by characteristics such as the mesoregion or population. The results show that the Rondoni municipalities had a high level of adherence to the compliance indicators for LRF and LAI. The lowest level of transparency was observed in the Porto Velho region, with an average General CI of $94 \%$. The most information available occurred in the region of Jaru, which obtained an average general IC of $97.33 \%$. Even in less populated municipalities, were found levels of compliance with full compliance, i.e. transparency, is not linked to the number of people living in a location or their economic capacity, but the commitment to meet the obligation to disclose public information.

Key-words: Transparency; Public management; Fiscal responsibility; Access to information.

\footnotetext{
${ }^{1}$ Engenheiro Ambiental. Universidade Federal Rural da Amazônia (UFRA). E-mail duartelleon@gmail.com

${ }^{2}$ Economista, Doutoranda em Agronomia na área de Socioeconomia, Recursos Naturais e Desenvolvimento pela Universidade Federal Rural da Amazônia (UFRA). E-mail: gea.marti@ yahoo.com.br

${ }^{3}$ Administrador, Doutorando em Agronomia na área de Socioeconomia, Recursos Naturais e Desenvolvimento pela Universidade Federal Rural da Amazônia (UFRA). E-mail: joaopaulo_loureiro@ hotmail.com

${ }^{4}$ Engenheiro Agrônomo, Doutor, Prof. do Programa de Pós-Graduação em Agronomia da Universidade Federal Rural da Amazônia, Área: Socioeconomia, Recursos Naturais e Desenvolvimento. marcos.marituba@gmail.com
} 


\section{INTRODUÇÃO}

A Lei de Responsabilidade Fiscal surgiu como um fator preponderante para fomentar o compromisso com a transparência na gestão pública do país, especificamente no setor fiscal, com a Lei $\mathrm{n}^{\circ} 101 / 2000$. Nesse cenário, outras leis de mesmo caráter foram surgindo nos anos seguintes, como a Lei da Transparência - nº131/2009 e ainda a criação da Lei de Acesso à Informação $\mathrm{n}^{\circ} 12.527 / 2011$, que tiveram como intuito, aproximar a relação entre o gestor público e a população e tornar obrigatória a publicidade das informações públicas em tempo real, como: receitas e despesas, por exemplo.

O grande objetivo, tanto da LRF quanto da LAI, é o de melhorar a governança pública e, consequentemente, a accountability, pois a primeira tem aspectos éticos e morais e o comportamento da liderança por objeto, enquanto a segunda facilita o controle e o monitoramento de atos administrativos e da conduta de agentes públicos (TCU, 2014).

Nesse sentido, a pesquisa tem o intuito de traçar características à cerca da execução da Lei de Responsabilidade Fiscal (LRF) e Lei de Acesso a Informação (LAI) como ferramenta de governança pública para responder a seguinte pergunta: Qual o nível de transparência dos municípios rondonienses em relação a Lei de Responsabilidade Fiscal e da Lei de Acesso à Informação? Com isso, a pesquisa pretende verificar quais os fatores que explicam o compromisso dos municípios de Rondônia com a transparência pública.

O princípio da transparência está ligado à divulgação, de maneira abrangente e compreensível, das informações que a população precisa saber sobre a situação econômica do Município, do Estado ou da União, como: arrecadação tributária, gastos públicos, dívida pública, etc. Esse princípio não é para que o Estado publique o orçamento somente, mas sua execução de forma clara. Isso garante que o Estado publique além do orçamento os relatórios fiscais, detalhando como os recursos públicos foram utilizados, qual foi o resultado obtido pelos investimentos, se ocorreu o cumprimento de metas, etc.

Juntamente com a identificação do nível de transparência dos municípios, o estudo fornece informações importantes aos gestores públicos e aos cidadãos sobre a condição da transparência de cada município. E ainda, são indicados também os principais elementos informativos da LRF e da LAI e identificados os municípios com diferentes níveis de transparência.

Devem ser submetidas à LRF a União, os Estados, o Distrito Federal e os Municípios, estando compreendidos o Poder Executivo, o Poder Legislativo, neste abrangidos os 
Tribunais de Contas, o Poder Judiciário e o Ministério Público. As respectivas administrações diretas, fundos, autarquias, fundações e empresas estatais dependentes (BRASIL, 2000).

Subordinam-se à LAI os órgãos públicos integrantes da administração direta dos Poderes Executivo e Legislativo, incluindo as Cortes de Contas, e Judiciário e do Ministério Público. As autarquias, as fundações públicas, as empresas públicas, as sociedades de economia mista e demais entidades controladas direta ou indiretamente pela União, Estados, Distrito Federal e Municípios (BRASIL, 2011).

A Lei de Responsabilidade Fiscal enfatiza a ação planejada e transparente na administração pública, isto é, a administração dos recursos públicos precisa ser baseada em planos previamente traçados e sujeitos à apreciação e aprovação pelo Poder Legislativo, garantindo-se a necessária legitimidade (Enap, 2017).

Segundo dados do Instituto Brasileiro de Geografia e Estatística (IBGE, 2019), o Estado de Rondônia possui uma população de 1.777.225 habitantes divididos em 52 municípios. No presente trabalho optou-se por investigar o nível de transparência em todos os municípios rondonienses, representando no total 52 municípios.

Quando se trata da divulgação de dados sobre a gestão pública, as fontes oficiais de divulgação, como o Diário Oficial, são fundamentais nesse trabalho, mas os jornais de grande circulação e alguns sites oficiais de internet também preenchem esse papel de agentes da transparência, e especificamente em municípios, são populares os boletins e murais de livre acesso, que se caracterizam por dar ciência e validação pública.

Segundo a análise de Silva (2013, p.22) “A população necessita de informações referentes a gestão das finanças públicas e participar de forma efetiva das decisões governamentais". Nessa perspectiva, o presente estudo se torna também relevante pela possibilidade do cidadão discutir a importância no acompanhamento da gestão, dos atos públicos, além de revelar aspectos da transparência das contas públicas.

\section{METODOLOGIA}

O presente estudo fez uma abordagem quantitativa, descritiva e documental dos dados levantados, descrevendo a sua função e suas especificações técnicas. Para a elaboração da pesquisa foram utilizados dados disponíveis nos portais eletrônicos das prefeituras dos municípios, caracterizando assim as fontes como secundárias. 
Para identificação das home pages dos municípios foi utilizada a plataforma de busca on-line do Google (www.google.com.br), utilizando como expressão de pesquisa "Transparência [nome do município]".

O conteúdo era acessado a partir do portal de transparência do site; na maioria dos casos da Prefeitura ou da Câmara Municipal do município. As informações não localizadas eram pesquisadas por meio do serviço de busca, caso esse fosse disponibilizado no site. Não houve dificuldade em encontrar as páginas dos municípios.

O espaço amostral da pesquisa é composto de 52 municípios do Estado de Rondônia e está distribuída em seis mesorregiões geográficas, que por sua vez estão agrupadas em duas regiões geográficas intermediárias, e a determinação dessa amostra analisada foi realizada com base nos dados do Instituto Brasileiro de Geografia e Estatística (IBGE, 2019). Com isso esses municípios foram separados em mesorregiões como mostra o Quadro 1.

Quadro 1 - Municípios da amostra divididos por mesorregiões

\begin{tabular}{|c|c|}
\hline Mesorregiões & Municípios \\
\hline Porto Velho & Candeias do Jamari, Guajará Mirim, Itapuã do Oeste, Nova Mamoré, Porto Velho \\
\hline Ariquemes & $\begin{array}{c}\text { Ariquemes, Alto Paraíso, Buritis, Cacaulândia, Campo Novo de Rondônia, Cujubim, Monte } \\
\text { Negro, Rio Crespo }\end{array}$ \\
\hline Jaru & Governador Jorge Teixeira, Jaru, Machadinho D'Oeste, Theobroma, Vale do Anari \\
\hline Ji-Paraná & $\begin{array}{c}\text { Alvorada d'Oeste, Costa Marques, Ji-Paraná, Mirante da Serra, Nova União, Ouro Preto do } \\
\text { Oeste, Presidente Médici } \\
\text { São Francisco do Guaporé, São Miguel do Guaporé, Seringueiras, Teixeirópolis, Urupá, Vale } \\
\text { do Paraíso }\end{array}$ \\
\hline Cacoal & $\begin{array}{l}\text { Alta Floresta d'Oeste, Alto Alegre dos Parecis, Cacoal, Castanheiras, Espigão d'Oeste, } \\
\text { Ministro Andreazza, Nova, Brasilândia d'Oeste, Novo Horizonte do Oeste, Parecis, Pimenta } \\
\text { Bueno, Primavera de Rondônia, Rolim de Moura, Santa Luzia d'Oeste, São Felipe d'Oeste }\end{array}$ \\
\hline Vilhena & $\begin{array}{c}\text { Cabixi, Cerejeiras, Chupinguaia, Colorado do Oeste, Corumbiara, Pimenteiras do Oeste, } \\
\text { Vilhena }\end{array}$ \\
\hline
\end{tabular}

Fonte: IBGE (2019)

Para o levantamento de dados, foram utilizados indicadores de conformidade, adaptados de Vieira (2014) Bianchi (2014) e Kronbauer (2014), com objetivo de averiguar se o que está exposto na LRF e na LAI está sendo atendido pelos municípios citados. Foram determinados no total 30 indicadores, sendo 15 indicadores relacionados as exigências da LRF e 15 referentes à LAI, como exposto no Quadro 2. 
Quadro 2 - Indicadores de conformidade da LRF e da LAI

\begin{tabular}{|c|c|c|c|c|c|}
\hline Item & $\begin{array}{l}\text { Base } \\
\text { Legal }\end{array}$ & Indicador LRF & Item & $\begin{array}{c}\text { Base } \\
\text { Legal }\end{array}$ & Indicador LAI \\
\hline 1 & Art. 48 & $\begin{array}{l}\text { Plano Plurianual (PPA) } \\
\text { vigente }\end{array}$ & 1 & Art. $5^{\circ}$ & $\begin{array}{l}\text { Informação disponibilizada de forma } \\
\text { transparente, clara e em linguagem } \\
\text { de fácil compreensão }\end{array}$ \\
\hline 2 & Art. 48 & $\begin{array}{c}\text { Planos Plurianuais (PPAs) } \\
\text { anteriores }\end{array}$ & 2 & Art. $7^{\circ}$ & $\begin{array}{l}\text { Orientação sobre os procedimentos } \\
\text { para solicitação de informação }\end{array}$ \\
\hline 3 & Art. 48 & $\begin{array}{c}\text { Lei de Diretrizes } \\
\text { Orçamentárias (LDO) vigente }\end{array}$ & 3 & Art. $8^{\circ}$ & $\begin{array}{l}\text { Informações quanto as suas } \\
\text { Competências }\end{array}$ \\
\hline 4 & Art. 48 & $\begin{array}{c}\text { Leis de Diretrizes } \\
\text { Orçamentárias (LDOs) } \\
\text { anteriores }\end{array}$ & 4 & Art. $8^{\circ}$ & $\begin{array}{l}\text { Informações quanto à estrutura } \\
\text { Organizacional }\end{array}$ \\
\hline 5 & Art. 48 & $\begin{array}{l}\text { Lei Orçamentária } \\
\text { Anual (LOA) vigente }\end{array}$ & 5 & Art. $8^{\circ}$ & $\begin{array}{c}\text { Divulgação de endereços e } \\
\text { Telefones }\end{array}$ \\
\hline 6 & Art. 48 & $\begin{array}{l}\text { Leis Orçamentárias Anuais } \\
\text { (LOAs) anteriores }\end{array}$ & 6 & Art. $8^{\circ}$ & $\begin{array}{l}\text { Divulgação de horários de } \\
\text { atendimento ao público }\end{array}$ \\
\hline 7 & Art. 48 & $\begin{array}{c}\text { Relatório Resumido da } \\
\text { Execução Orçamentária } \\
\text { (RREO) }\end{array}$ & 7 & Art. $8^{\circ}$ & $\begin{array}{c}\text { Informações relativas a repasses ou } \\
\text { transferências de recursos } \\
\text { financeiros }\end{array}$ \\
\hline 8 & Art. 48 & $\begin{array}{l}\text { Relatório de Gestão Fiscal } \\
\text { (RGF) }\end{array}$ & 8 & Art. $8^{\circ}$ & Informações sobre as despesas \\
\hline 9 & Art. 48 & $\begin{array}{l}\text { Versão simplificada do } \\
\text { RREO }\end{array}$ & 9 & Art. $8^{\circ}$ & $\begin{array}{c}\text { Informações sobre licitações, editais } \\
\text { e seus resultados e demais contratos } \\
\text { celebrados }\end{array}$ \\
\hline 10 & Art. 48 & Versão simplificada do RGF & 10 & Art. $8^{\circ}$ & $\begin{array}{l}\text { Informações gerais para } \\
\text { acompanhamento de programas, } \\
\text { ações, projetos e obras }\end{array}$ \\
\hline 11 & Art. 48 & $\begin{array}{l}\text { Relatório de prestação de } \\
\text { contas }\end{array}$ & 11 & Art. $8^{\circ}$ & $\begin{array}{c}\text { Disponibilização de "respostas e } \\
\text { perguntas" mais frequentes da } \\
\text { sociedade }\end{array}$ \\
\hline 12 & Art. 48 & $\begin{array}{l}\text { Parecer prévio de prestação } \\
\text { de contas }\end{array}$ & 12 & Art. $8^{\circ}$ & $\begin{array}{c}\text { Disponibilização de ferramenta de } \\
\text { pesquisa }\end{array}$ \\
\hline 13 & Art. 48 & $\begin{array}{c}\text { Incentivo à participação } \\
\text { popular e audiências públicas } \\
\text { na elaboração e discussão do } \\
\text { PPA, LDO e LOA }\end{array}$ & 13 & Art. $8^{\circ}$ & $\begin{array}{l}\text { Permissão para gravação de } \\
\text { relatórios eletrônicos }\end{array}$ \\
\hline 14 & Art. 48 & $\begin{array}{c}\text { Informações de execução } \\
\text { orçamentária e financeira em } \\
\text { tempo real }\end{array}$ & 14 & Art. $8^{\circ}$ & $\begin{array}{c}\text { Conteúdo acessível a pessoas com } \\
\text { deficiência }\end{array}$ \\
\hline 15 & Art. $9^{\circ}$ & $\begin{array}{c}\text { Divulgação das datas de } \\
\text { audiências públicas } \\
\text { quadrimestrais para avaliação } \\
\text { das metas fiscais }\end{array}$ & 15 & Art. $9^{\circ}$ & $\begin{array}{l}\text { Serviço de Informações ao Cidadão } \\
\text { (SIC) }\end{array}$ \\
\hline
\end{tabular}

Fonte: Adaptado Vieira (2014) Bianchi (2014) e Kronbauer (2014).

Os dados analisados também foram obtidos em portais eletrônicos das prefeituras durante o período de setembro e outubro de 2019. Foram realizados levantamentos de dados 
nos portais para averiguar o cumprimento de cada indicador. A análise desses dados foi feita seguindo a metodologia de Vieira (2014) Bianchi (2014) Kronbauer (2014), assim para cada indicador encontrado e confirmado foi considerado um ponto. Na situação de não constar a divulgação da informação, foi atribuído a pontuação zero. Ao final, foram somadas as pontuações dos indicadores por município, sendo que cada um poderia ter no máximo, por lei, 15 pontos.

Com relação aos indicadores de conformidade relacionados ao PPA, considerou-se como vigente o PPA referente aos anos entre 2018 a 2021, e anterior, aos anos de 2014 a 2017. Para à LDO e à LOA, foi considerada como vigente as leis referentes ao ano de 2019 e anteriores às de 2018.

Todos os itens disponibilizados, por município, foram divididos por todos os itens que deveriam ter sido disponibilizados, de acordo com o Quadro 2. Deste modo, o total de indicadores disponibilizados foi dividido por 15, e assim foram calculados os seguintes índices de conformidade: Índice de Conformidade à LRF (IC LRF); Índice de Conformidade à LAI (IC LAI); e Índice de Conformidade Geral (IC Geral).

Com relação ao IC Geral, foram somados todos os indicadores disponibilizados e divididos por 30. Em seguida, os valores achados foram calculados para índices percentuais. Com o auxílio de tabela e gráficos, que serão vistos nos próximos tópicos, os índices percentuais calculados foram estudados com a ajuda da estatística descritiva.

\section{RESULTADOS}

\subsection{Análise geral da amostra}

Na primeira parte da análise serão apresentados os índices gerais de adesão à LRF e à LAI no Estado de Rondônia (RO), como mostra a Tabela 1 a seguir. Nesta tabela são apresentados os dados da estatística descritiva acerca das informações disponibilizadas pelos municípios referente ao Índice de Conformidade da LRF, Índice de Conformidade da LAI e do Índice de Conformidade Geral, que se refere a divulgação de forma conjunta entre essas 2 leis.

Legenda: IC Geral = Índice de Conformidade Geral; IC LRF = Índice de Conformidade com a Lei de Responsabilidade Fiscal; IC LAI = Índice de Conformidade com a Lei Acesso à Informação. 
Tabela 1 - Estatística Descritiva da Amostra

\begin{tabular}{cccc}
\hline Estatística Descritiva & IC LRF & IC LAI & IC GERAL \\
\hline Média & 92,54 & 98,58 & 95,57 \\
Erro Padrão & 1,26 & 0,38 & 0,67 \\
Mediana & 93,33 & 100 & 96,66 \\
Modo & 100 & 100 & 100 \\
Desvio Padrão & 9,11 & 2,74 & 4,83 \\
Variância & 83,05 & 7,55 & 23,40 \\
Intervalo & 33,33 & 6,66 & 20 \\
Curtose & 0,29 & 0,12 & 0,75 \\
Assimetria & $-1,12$ & $-1,45$ & $-1,07$ \\
Mínimo & 66,66 & 93,33 & 80 \\
Máximo & 100 & 100 & 100 \\
Soma & 4813,33 & 5126,66 & 4970 \\
Contagem & 52 & 52 & 52 \\
Nível de Confiança & 2,53 & 0,76 & 1,34 \\
\hline
\end{tabular}

Fonte: Dados da pesquisa (2019)

A partir da Tabela 1 pode-se interpretar que o grau de adesão à LRF e à LAI dos municípios é alto, apresentando Média do Índice de Conformidade GERAL de 95,57\%. Somando-se a isso, o Índice de Conformidade a LAI foi o que apresentou o maior grau de adesão com Média de 98,58\%, superior ao IC GERAL, e considerando que teve uma Mínima de 93,33\%, ou seja pelo menos 13 indicadores satisfatórios (13 indicadores, dentre os 15), e Máxima de 100\%, o que mostra um alto grau de atendimento as Leis de Acesso à Informação.

Em relação a Média do Índice de Conformidade à LRF foi de 92,54\%, apesar de um pouco abaixo do IC da LAI, é um valor alto demostrando que a grande maioria dos municípios rondonienses estão em dia com a transparência das contas públicas. Contudo, a Mínima do IC da LRF ficou em 66,66\%, demostrando que pelo menos 9 indicadores tiveram resultado satisfatório (9 indicadores, dentre os 15), bem abaixo da Mínima do IC da LAI. Mais à frente no estudo, veremos que isso se deve principalmente ao Parecer Prévio de Prestação de Contas, em que os municípios menos populosos apresentaram uma característica em comum de não divulgação desse parecer.

Quando comparados os dados de desempenho do estudado de Vieira, Bianchi e Kronbauer (2014), os resultados dos municípios de Rondônia, conforme na Tabela 1, foram 
muito superiores aos da amostra do Estado do Rio Grande do Sul, considerando que a Mediana do IC Geral dos municípios do RS foi de 66,67, e em Rondônia de 96,66. A Mediana do IC LRF apresentou uma diferença ainda maior, enquanto no Rio Grande do Sul a mais elevada foi igual a 60 , nos municípios rondonienses, a que teve menor desempenho foi de 93,33 .

O máximo tanto do Índice de Conformidade da LRF e da LAI foi igual, de 100\%. Isso significa que ao menos um município conseguiu atingir todos os indicadores tanto da Lei de Responsabilidade de Fiscal ou da Lei de Acesso à Informação. Coincidentemente no estudo de Vieira, Bianchi e Kronbauer (2014) o Máximo para IC LAI também foi de 100\%. Contudo, para IC LRF o percentual máximo foi 93,33, o que significa que nenhum município conseguiu atender a todas as exigências.

Vale salientar que os resultados encontrados no presente estudo são ainda mais expressivos quando comparados com aqueles encontrados por Silva (2013). Enquanto o Estado de Rondônia teve medianas de 93,33, 100, e 96,66 para IC LRF, IC LAI, IC GERAL, respectivamente. O Estado do Mato Grosso teve medianas de 34,38, 16,67 e 25 para IC LRF, IC LAI e IC GERAL, respectivamente. Acrescentando que os municípios mato-grossenses tiveram mínimas de 0,00 , ou seja, nenhum município aderiu as exigências por completo.

\subsection{Análise de conformidade por mesorregião}

Esse tópico apresenta os índices de conformidade de cada lei e geral obtidos em cada município das mesorregiões geográficas de Rondônia. Na Tabela 2 foram relacionados os índices de conformidade dos municípios que compõe a Mesorregião de Porto Velho: Candeias do Jamari, Guajará Mirim, Itapuã do Oeste, Nova Mamoré e Porto Velho.

Tabela 2 - Índice de Conformidade da Mesorregião de Porto Velho

\begin{tabular}{ccccc}
\hline $\boldsymbol{N}^{\boldsymbol{o}}$ & Municípios & IC LRF \% & IC LAI \% & IC GERAL \% \\
\hline 1 & Candeias do Jamari & 100 & 100 & 100 \\
2 & Guajará Mirim & 100 & 93,33 & 96,66 \\
3 & Itapuã do Oeste & 86,66 & 100 & 93,33 \\
4 & Nova Mamoré & 66,66 & 93,33 & 80 \\
5 & Porto Velho & 100 & 100 & 100 \\
& Média Região Porto & $\mathbf{9 0 , 6 6}$ & $\mathbf{9 7 , 3 3}$ & $\mathbf{9 3 , 9 9}$ \\
& Velho & & & \\
\hline
\end{tabular}

Fonte: Dados da pesquisa (2019) 
Na Tabela 2 nota-se que todos os municípios da mesorregião de Porto Velho apresentam alto grau de aderência á LAI. Destaque para os municípios de Candeias do Jamari e Porto Velho com $100 \%$ para todos os Índices de Conformidade. Itapuã do Oeste e Nova Mamoré foram os únicos municípios que ficaram a baixo da média do IC LRF, com 86,66\% e 66,66\%. Com isso, percebe-se que para transparência da LRF o município de Nova Mamoré ainda está aquém do esperado, no IC GERAL foi o único da região que ficou abaixo da média, com $80 \%$. Vale ressaltar, dos municípios que não atingiram os $100 \%$ para todos os IC, o município de Guajará Mirim foi o único com IC LRF maior que o IC LAI e IC GERAL.

$\mathrm{Na}$ Tabela 3 estão relacionados os municípios que compõem a Mesorregião de Ariquemes: Ariquemes, Alto Paraíso, Buritis, Cacaulândia, Campo Novo de Rondônia, Cujubim, Monte Negro, Rio Crespo e seus índices de conformidade.

Tabela 3 - Índice de Conformidade da Mesorregião de Ariquemes

\begin{tabular}{ccccc}
\hline${ }^{\prime}{ }^{\boldsymbol{o}}$ & Municípios & IC LRF \% & IC LAI \% & IC GERAL \% \\
1 & Ariquemes & 100 & 100 & 100 \\
2 & Alto Paraíso & 100 & 93,33 & 96,66 \\
3 & Buritis & 100 & 100 & 100 \\
4 & Cacaulândia & 100 & 100 & 100 \\
5 & Campo Novo de Rondônia & 100 & 100 & 100 \\
6 & Cujubim & 73,33 & 100 & 86,66 \\
7 & Monte Negro & 100 & 100 & 100 \\
8 & Rio Crespo & 73,33 & 100 & 86,66 \\
& Média Região Ariquemes & $\mathbf{9 3 , 3 3}$ & $\mathbf{9 9 , 1 6}$ & $\mathbf{9 6 , 2 4}$ \\
\hline
\end{tabular}

Fonte: Dados da pesquisa (2019)

Na tabela 3 destaque para os municípios de Ariquemes, Buritis, Cacaulândia, Campo Novo de Rondônia e Monte Negro, que tiveram o Índice de Conformidade Geral de $100 \%$. Cujubim e Rio Crespo apresentaram 73,33\% no IC LRF valor aquém dos outros municípios da região, que tiveram ao menos $93,33 \%$ para esse índice.

Entre todos os municípios da região, Alto Paraiso com 93,33\% foi o único que não teve $100 \%$ para o Índice de Conformidade da Lei de Acesso à Informação. Curiosamente esse mesmo município foi o único que teve IC LRF maior que IC LAI e IC GERAL, com 100\%, $93,33 \%$ e 96,66\%, respectivamente. Isso significa que houve maior grau de divulgação da execução orçamentária em detrimento da divulgação das formas de solicitação de informação. 
A Tabela 4 foi criada com informações coletadas da Mesorregião de Jaru, representada pelos seguintes municípios com os seus índices de conformidade: Governador Jorge Teixeira, Jaru, Machadinho D'Oeste, Theobroma e Vale do Anari.

Tabela 4 - Índice de Conformidade da Mesorregião de Jaru

\begin{tabular}{ccccc}
\hline$N^{\boldsymbol{o}}$ & Municípios & IC LRF \% & IC LAI \% & IC GERAL \% \\
1 & Governador Jorge Teixeira & 100 & 100 & 100 \\
2 & Jaru & 100 & 100 & 100 \\
3 & Machadinho D'Oeste & 100 & 100 & 100 \\
4 & Theobroma & 80 & 100 & 90 \\
5 & Vale do Anari & 93,33 & 100 & 96,66 \\
& Média Região Jaru & $\mathbf{9 4 , 6 6 6}$ & $\mathbf{1 0 0}$ & $\mathbf{9 7 , 3 3 2}$ \\
\hline
\end{tabular}

Fonte: Dados da pesquisa (2019)

A Tabela 4 evidencia que não existe grande diferença entre os municípios da região de Jaru. Governador Jorge Teixeira, Jaru e Machadinho do Oeste também são referência tanto na divulgação completa da execução orçamentária quanto na transparência das informações. Esses municípios apresentam 100\% tanto para IC LRF, IC LAI quanto para IC GERAL. Theobroma e Vale do Anari foram os únicos municípios que não atenderam a todas as exigências de divulgação das informações de execução orçamentaria, representando $80 \%$ e 93,33\%, respectivamente. Com isso, acabou refletindo no seu Índice de Conformidade Geral, onde Theobroma teve o menor índice entre todos (90\%), seguido de Vale do Anari $(96,66 \%)$.

Os 13 municípios que compõe a Mesorregião de Ji-Paraná, do Estado de Rondônia, estão presentes na Tabela 5, com os seus índices de conformidade.

Tabela 5 - Índice de Conformidade da Mesorregião de Ji-Paraná

\begin{tabular}{ccccc}
\hline $\boldsymbol{N}^{\boldsymbol{o}}$ & Municípios & IC LRF \% & IC LAI \% & IC GERAL \% \\
\hline 1 & Alvorada d'Oeste & 100 & 100 & 100 \\
2 & Costa Marques & 93,33 & 100 & 96,66 \\
3 & Ji-Paraná & 100 & 93,33 & 96,66 \\
4 & Mirante da Serra & 93,33 & 100 & 96,66 \\
5 & Nova União & 100 & 100 & 93,33 \\
7 & Ouro Preto do Oeste & 93,33 & 93,33 & 93,33 \\
8 & Presidente Médici & 93,33 & 93,33 & 100
\end{tabular}


9

10

11

12

13
São Miguel do Guaporé

Seringueiras

Teixeirópolis

Urupá

Vale do Paraíso

Média Região Ji-Paraná
73,33

86,66

93,33

93,33

100

93,84
100

93,33

100

93,33

100

$\mathbf{9 7 , 4 3}$
86,66

90

96,66

93,33

100

95,63

Fonte: Dados da pesquisa (2019)

A Tabela 5 mostra que todos os municípios da região de Ji-Paraná tiveram excelente desempenho, com destaque para Alvorada do Oeste, Nova União, São Francisco do Guaporé e Vale do Paraíso que atenderam a todas as exigências às Lei de Responsabilidade Fiscal e de Acesso à Informação, completando 100\% de Índice de Conformidade Geral.

Apesar do município de São Miguel do Guaporé ter apresentado todas as exigências ao IC LAI, o seu IC LRF ficou ligeiramente abaixo com 73,33 e representando o menor índice entre todos os municípios, o que significa, que a divulgação dos planos orçamentários dessa região não foi cumprida na integralidade, fazendo com que o IC Geral, de 86,66, também fosse o menor, mas ainda assim apresentando bom desempenho. Outro município que apresentou um bom desempenho, mas que também ficou um pouco aquém em relação aos seus vizinhos foi o município de Seringueiras, com 86,66\%, 93,33\% e 90\% para IC LRF, IC LAI e IC Geral, respectivamente. A seguir a Tabela 6 revela dados acerca da transparência dos 14 municípios de Cacoal.

Tabela 6 - Índice de Conformidade da Mesorregião de Cacoal

\begin{tabular}{ccccc}
\hline $\boldsymbol{N}^{\boldsymbol{o}}$ & Municípios & IC LRF \% & IC LAI \% & IC GERAL \% \\
\hline 1 & Alta Floresta d'Oeste & 80 & 100 & 90 \\
2 & Alto Alegre dos Parecis & 93,33 & 100 & 96,66 \\
3 & Cacoal & 86,66 & 100 & 93,33 \\
4 & Castanheiras & 80 & 100 & 90 \\
5 & Espigão d'Oeste & 80 & 100 & 90 \\
6 & Ministro Andreazza & 100 & 100 & 100 \\
7 & Nova Brasilândia d'Oeste & 100 & 100 & 100 \\
8 & Novo Horizonte d'Oeste & 100 & 100 & 100 \\
9 & Parecis & 93,33 & 100 & 96,66 \\
10 & Pimenta Bueno & 93,33 & 100 & 96,66 \\
11 & Primavera de Rondônia & 93,33 & 100 & 96,66
\end{tabular}




$\begin{array}{lcccc}12 & \text { Rolim de Moura } & 86,66 & 100 & 93,33 \\ 13 & \text { Santa Luzia do Oeste } & 93,33 & 100 & 96,66 \\ 14 & \text { São Felipe d'Oeste } & 100 & 100 & 100 \\ & \text { Média Região Cacoal } & \mathbf{9 1 , 4 2} & \mathbf{1 0 0} & \mathbf{9 5 , 7 1}\end{array}$

Fonte: Dados da pesquisa (2019)

Os 14 municípios da Mesorregião de Cacoal comprovam uma característica importante que foi vista nas outras mesorregiões do Estado de Rondônia, mostrando que a divulgação das informações exigidas pelas leis de acesso à informação está sendo feita de forma transparente, apresentando um desempenho interessante na maioria dos municípios rondonienses. Inclusive com os resultados sendo bem superiores a divulgação dos planos orçamentários exigidos pela LRF, também na maioria dos municípios.

Todos os municípios apresentaram 100\% Índice de Conformidade as leis de Acesso à Informação. Destaque para os municípios de Ministro Andreazza, Nova Brasilândia do Oeste, Novo Horizonte do Oeste e São Felipe do Oeste, que além do IC LAI, apresentaram todas as exigências do planejamento orçamentário dos municípios com $100 \%$ para o Índice de Conformidade as leis de responsabilidade fiscal.

Alta Floresta d'Oeste, Castanheiras e Espigão do Oeste deixaram de prestar contas de alguns indicadores orçamentários e com isso ficaram com os menores valores para IC LRF referente a região do Cacoal, consequentemente também com os menores valores para IC Geral dessa região. Curiosamente ficaram com as mesmas porcentagens para ambos os índices, $80 \%$ e $90 \%$, respectivamente.

Os municípios apresentados na Tabela 7, apenas Cabixi e Colorado do Oeste realizaram a publicidade do seu planejamento orçamentário e dos dados de acesso a informação, com isso ficaram com $100 \%$ em todos os índices de conformidade. O município de Cerejeiras também está em dia com o plano orçamentário, apresentando $100 \%$ para IC LRF, porém falhou na divulgação de um indicador de LAI e acabou ficando com 93,33\% e IC Geral de 96,66\%.

Tabela 7 - Índice de Conformidade da Mesorregião de Vilhena

\begin{tabular}{ccccc}
\hline $\boldsymbol{N}^{\boldsymbol{o}}$ & Municípios & IC LRF \% & IC LAI \% & IC GERAL \% \\
\cline { 2 - 5 } 1 & Cabixi & 100 & 100 & 100 \\
2 & Cerejeiras & 100 & 93,33 & 96,66 \\
3 & Chupinguaia & 93,33 & 93,33 & 93,33
\end{tabular}




$\begin{array}{ccccc}4 & \text { Colorado do Oeste } & 100 & 100 & 100 \\ 5 & \text { Corumbiara } & 80 & 100 & 90 \\ 6 & \text { Pimenteiras d'Oeste } & 80 & 93,33 & 86,66 \\ 7 & \text { Vilhena } & 86,66 & 100 & 93,33 \\ & \text { Média Região Vilhena } & \mathbf{9 1 , 4 2} & \mathbf{9 7 , 1 4} & \mathbf{9 4 , 2 8}\end{array}$

Fonte: Dados da pesquisa (2019)

Corumbiara e Pimenteiras do Oeste tiveram os mesmos índices de conformidade relativos a LRF, com $80 \%$, isso deve-se a ausência do parecer prévio de 2018. Com isso, esses municípios ficaram com os menores índices de conformidade em relação a LRF entre todos os municípios da região. Sendo que o próprio município de Pimenteiras do Oeste teve o menor IC Geral entre essa amostra.

Para concluir esta seção de verificação da conformidade dos municípios relacionados por Mesorregião, foi criado o Gráfico 1, que busca demostrar o nível de adesão de cada região às leis pesquisadas.

Gráfico 1 - Índices de conformidade por mesorregião

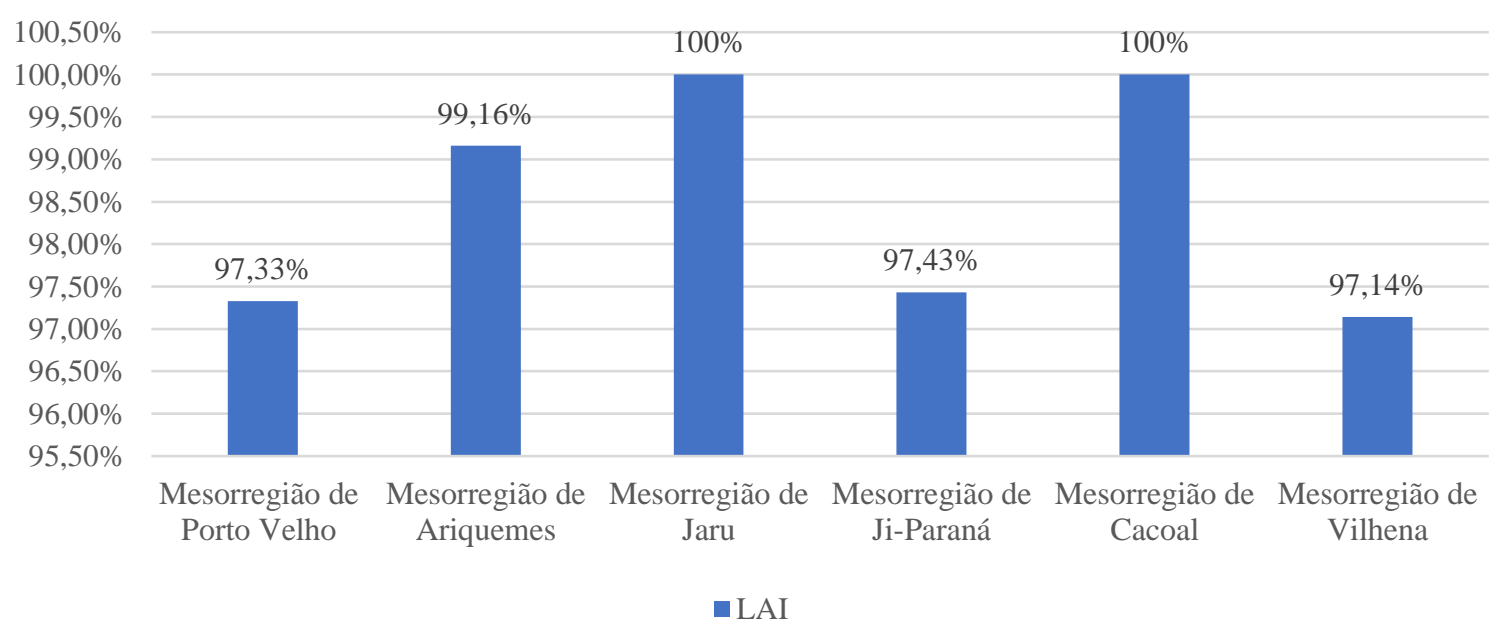

Fonte: Dados da pesquisa (2019)

A partir do Gráfico 1 pode-se concluir que o grau de aderência à LAI é alto em todas as regiões. Expressando que a maioria das prefeituras atendem as exigências da Lei de Acesso à Informação. Destaque para a Mesorregião de Cacoal e de Jaru, que apresentaram 100\% para LAI, disponibilizando todas as informações básicas exigidas para a LAI. Com relação a LRF, os indicadores também mostraram um grau de adesão alto, mesmo a Mesorregião de Porto Velho que apresentou o menor grau de atendimento aos indicadores de transparência dos planos orçamentários, teve excelente desempenho com $90,66 \%$. 
Se comparados com o estudo de Vieira, Bianchi e Kronbauer (2014), nota-se que no Estado do Rio Grande do Sul, também existe maior aderência aos indicadores das leis de acesso à informação. Em se tratando da LRF, as mesorregiões rio-grandenses estão muito abaixo das mesorregiões rondonienses, o maior resultado obtido naquele Estado foi do Centro Oriental Rio-Grandense com $72 \%$, e o menor entre as regiões rondonienses foi de $90,66 \%$ da Mesorregião de Porto Velho.

Os Índices de Conformidade Geral encontrados variaram de 93,99\% a 97,33\%, sendo o pior desempenho apresentado pela Mesorregião de Porto Velho e a Região mais transparente, Mesorregião do Jaru. Curiosamente as duas regiões possuem a mesma quantidade de municípios. O IC Geral Médio do Estado foi 95,53\%, composto pelos 92,56\% de conformidade com a LRF, e 98,51\% com a LAI. Entre os 52 municípios, somente 33 revelaram IC Geral acima da Médio do Estado.

O Estado de Rondônia, como dito anteriormente, possui um rol de municípios que são referência em transparência, ou seja, tiveram 100\% de IC Geral, são eles: Porto Velho, Candeias do Jamari, Ariquemes, Buriti, Cacaulândia, Campo Novo de Rondônia, Monte Negro, Ministro Andreazza, Nova Brasilândia d'Oeste, Novo Horizonte do Oeste, São Felipe D'Oeste, Governador Jorge Teixeira, Jaru, Machadinho D'Oeste, Alvorada d'Oeste, Nova União, São Francisco do Guaporé, Vale do Paraíso, Cabixi e Colorado do Oeste. O menor índice ficou com Nova Mamoré, 80\%. Mesmo abaixo dos demais munícios rondonienses na divulgação de informações exigidas por lei, ainda ficou muito acima da maioria dos munícios rio-grandenses no estudo de Vieira, Bianchi e Kronbauer (2014).

É importante ressaltar novamente que os municípios de Rondônia apresentaram pouca disparidade em pontos percentuais, mesmo os municípios menos populosos ou com menos poder econômico, que se espera que tenha um desempenho inferior aos mais populosos e/ou com maior poder econômico, demonstraram um excelente grau de aderência as leis que exigem maior transparência das contas públicas e de solicitação das informações que são de direito do cidadão. Dessa forma, percebe-se que o estado é uma boa referência no país em termos de aderência as leis de responsabilidade fiscal e de acesso à informação.

\subsection{Análise de conformidade por indicador}

A análise de cada indicador por mesorregião é apresentada nas Tabelas 7 e 8 , que relacionam os itens da Lei de Responsabilidade Fiscal e da Lei de Acesso à Informação aplicados na pesquisa, respectivamente, e a totalidade observada por mesorregião. A Tabela 8, 
abaixo, mostra os indicadores aplicados relativos à LRF, objetivando revelar o percentual de adesão às leis estudadas, para cada indicador e para cada mesorregião.

Legenda: I = Região Porto Velho; II = Região Ariquemes; III = Região Jaru; IV = Região Ji-Paraná; V = Região Cacoal; VI = Região Vilhena.

Tabela 8 - Conformidade por indicador da LRF por mesorregião

\begin{tabular}{|c|c|c|c|c|c|c|c|c|}
\hline $\begin{array}{l}\text { Indicadores } \\
\text { Mesorregião }\end{array}$ & $\begin{array}{c}\text { M } \\
\mathbf{I}\end{array}$ & $\begin{array}{l}\text { M } \\
\text { II }\end{array}$ & $\begin{array}{l}\text { M } \\
\text { III }\end{array}$ & $\begin{array}{l}\text { M } \\
\text { IV }\end{array}$ & $\begin{array}{l}\mathbf{M} \\
\mathbf{V}\end{array}$ & $\begin{array}{l}\text { M } \\
\text { VI }\end{array}$ & Total & $\%$ \\
\hline Versão simplificada RREO & 5 & 7 & 5 & 13 & 14 & 6 & 50 & $96 \%$ \\
\hline Versão simplificada do RGF & 5 & 7 & 5 & 12 & 13 & 7 & 49 & $94 \%$ \\
\hline RGF & 5 & 7 & 5 & 13 & 14 & 7 & 51 & $98 \%$ \\
\hline PPA vigente & 4 & 8 & 5 & 13 & 14 & 7 & 51 & $98 \%$ \\
\hline $\begin{array}{c}\text { Incentivo à participação popular e } \\
\text { audiências públicas no processo de } \\
\text { elaboração e discussão de PPA, LDO e } \\
\text { LOA }\end{array}$ & 4 & 7 & 4 & 11 & 10 & 5 & 41 & $79 \%$ \\
\hline LDO vigente & 5 & 8 & 5 & 13 & 14 & 7 & 52 & $100 \%$ \\
\hline $\begin{array}{c}\text { Informações de execução orçam. e financ. - } \\
\text { tempo real }\end{array}$ & 5 & 7 & 5 & 12 & 14 & 7 & 50 & $96 \%$ \\
\hline LDOs anteriores & 5 & 8 & 5 & 13 & 14 & 7 & 52 & $100 \%$ \\
\hline LOA vigente & 4 & 8 & 5 & 13 & 14 & 6 & 50 & $96 \%$ \\
\hline RREO & 5 & 7 & 5 & 13 & 14 & 7 & 51 & $98 \%$ \\
\hline LOAs anteriores & 4 & 8 & 5 & 13 & 13 & 7 & 50 & $96 \%$ \\
\hline PPAs anteriores & 5 & 8 & 5 & 13 & 14 & 7 & 52 & $100 \%$ \\
\hline Relatório de prestação de conta & 4 & 8 & 5 & 13 & 14 & 7 & 51 & $98 \%$ \\
\hline $\begin{array}{c}\text { Divulgação das datas de audiências públicas } \\
\text { quadrimestrais para avaliação das metas } \\
\text { fiscais }\end{array}$ & 4 & 7 & 5 & 10 & 8 & 6 & 38 & $73 \%$ \\
\hline Parecer prévio de prestação de contas & 4 & 7 & 3 & 10 & 7 & 3 & 34 & $65 \%$ \\
\hline
\end{tabular}

Fonte: Dados da pesquisa (2019)

A partir da Tabela pode-se notar que a maioria dos itens teve a porcentagem de divulgação muito satisfatória. Isso se justifica quando os três instrumentos do modelo orçamentário brasileiro, segundo a Constituição Federal de 1988, o Plano Plurianual - PPA, a Lei de Diretrizes Orçamentárias - LDO e a Lei Orçamentária Anual - LOA, apresentaram de $96 \%$ a $100 \%$, seja do modelo vigente ou dos anos anteriores.

O Parecer Prévio é um valioso instrumento de transparência das gestões públicas, que favorece o controle social das contas públicas e fortalece o exercício da cidadania, no Estado Democrático de Direito, foi encontrado em apenas 65\% dos municípios, ficando bem abaixo dos demais indicadores orçamentários, inclusive o Relatório de Prestação de Contas, onde deve se inserir o PP, está sendo divulgado sem o PP vigente por uma boa parte dos municípios, já que teve $98 \%$ de divulgação.

Para o indicador de incentivo à participação popular, foram consideradas todas notícias e convocações dispostas em portais eletrônicos disponibilizando datas e locais das 
audiências públicas, que estivessem ligadas com a elaboração e discussão de PPA, LDO e LOA. A adesão foi alta, considerando que as prefeituras da Mesorregião de Cacoal foram as que ficaram devendo esse incentivo à participação popular em comparação com as outras, sendo que do total de municípios (14), 10 demonstraram que estão cientes da importância de convocar a população para o debate das contas públicas.

Já o incentivo a participação popular por meio das as audiências públicas, ficaram no percentual de $79 \%$, demostrando que a participação popular é importante para grande maioria dos municípios e que o meio eletrônico está sendo positivo como ferramenta democrática.

A Região de Cacoal também em outro indicador que envolve as audiências públicas, dessa vez trata-se da divulgação das datas quadrimestrais para avaliação das metas fiscais. Dos 14 municípios da região, apenas 8 prefeituras apresentaram essas datas quadrimestrais. $\mathrm{O}$ que acabou refletindo no percentual total do indicador com 73\%. Mesmo com esse déficit, ficou mais de três vezes acima, em pontos percentuais, para o mesmo indicador na pesquisa de Vieira, Bianchi e Kronbauer (2014), tendo um resultado insatisfatório de apenas 20\%. A única mesorregião que apresentou a divulgação de todas as datas para avaliação das metas fiscais foi a de Jaru, assim seguindo a ideia de Conte e Santos (2014, p. 18), "o dever de dar a mais ampla publicidade aos atos administrativos e de gestão, possibilitando, com isso, a transparência, o conhecimento e a fiscalização da legitimidade de seus atos pelos administrados".

O incentivo à participação popular e a realização de audiências públicas, a liberação de informações pormenorizadas sobre a execução orçamentária e financeira - em meios eletrônicos de acesso público - e a adoção de um sistema integrado de administração financeira e controle são outras formas de garantir a transparência das informações garantidas pela Lei da Transparência (BRASIL, 2009). Analisando Tabela 7 nota-se que as regiões do Estado de Rondônia estão realizando essas medidas, visto que dos 52 municípios analisados, apenas 2 não divulgaram as informações de execução orçamentarias ou não disponibilizaram em tempo real.

Assim como no trabalho de Vieira, Bianchi e Kronbauer (2014), a versão simplificada do relatório resumido de execução orçamentária foi divulgada em quase toda a sua totalidade pelas prefeituras rondonienses. Com $93 \%$ para os municípios rio-grandenses, enquanto os do Estado de Rondônia apresentaram 96\%. Já no estudo de Marques (2014), o resultado foi bem inferior, com menos da metade das prefeituras divulgando esse relatório simplificado e sendo o mais divulgado entre todos os indicadores $45,74 \%$. 
A Tabela 9, abaixo, mostra os indicadores referentes à LAI, o percentual de atendimento à essa lei, por indicador e por mesorregião.

Legenda I = Região Porto Velho; II = Região Ariquemes; III = Região Jaru; IV = Região Ji-Paraná; V = Região Cacoal; VI = Região Vilhena.

Tabela 9 - Conformidade por indicador da LAI por mesorregião

\begin{tabular}{|c|c|c|c|c|c|c|c|c|}
\hline $\begin{array}{l}\text { Indicadores } \\
\text { Mesorregiões }\end{array}$ & $\begin{array}{c}\mathbf{M} \\
\mathbf{I}\end{array}$ & $\begin{array}{l}\text { M } \\
\text { II }\end{array}$ & $\begin{array}{l}\text { M } \\
\text { III }\end{array}$ & $\begin{array}{l}\text { M } \\
\text { IV }\end{array}$ & $\begin{array}{l}\mathbf{M} \\
\mathbf{V}\end{array}$ & $\begin{array}{l}\mathbf{M} \\
\mathbf{V I}\end{array}$ & Total & $\%$ \\
\hline $\begin{array}{c}\text { Informações quanto à estrutura } \\
\text { organizacional }\end{array}$ & 5 & 8 & 5 & 13 & 14 & 7 & 52 & $100 \%$ \\
\hline $\begin{array}{l}\text { Divulgação de endereços e } \\
\text { telefones }\end{array}$ & 5 & 8 & 5 & 13 & 14 & 7 & 52 & $100 \%$ \\
\hline $\begin{array}{l}\text { Permissão para gravação de } \\
\text { relatórios eletrônicos }\end{array}$ & 5 & 8 & 5 & 13 & 14 & 7 & 52 & $100 \%$ \\
\hline Informações sobre as despesas & 5 & 8 & 5 & 13 & 14 & 7 & 52 & $100 \%$ \\
\hline $\begin{array}{l}\text { Informações sobre licitações, } \\
\text { editais e seus resultados e demais } \\
\text { contratos celebrados Informações } \\
\text { sobre licitações, editais e seus } \\
\text { resultados e demais contratos } \\
\text { celebrados }\end{array}$ & 5 & 8 & 5 & 13 & 14 & 7 & 52 & $100 \%$ \\
\hline $\begin{array}{l}\text { Disponibilização de ferramenta de } \\
\text { pesquisa }\end{array}$ & 4 & 7 & 5 & 9 & 14 & 4 & 43 & $83 \%$ \\
\hline $\begin{array}{l}\text { Informações quanto as suas } \\
\text { competências }\end{array}$ & 5 & 8 & 5 & 13 & 14 & 7 & 52 & $100 \%$ \\
\hline $\begin{array}{l}\text { Divulgação de horários de } \\
\text { atendimento ao público }\end{array}$ & 5 & 8 & 5 & 13 & 14 & 7 & 52 & $100 \%$ \\
\hline $\begin{array}{c}\text { Informações relativas aos repasses } \\
\text { e transferências de recursos } \\
\text { financeiros }\end{array}$ & 5 & 8 & 5 & 13 & 14 & 7 & 52 & $100 \%$ \\
\hline $\begin{array}{l}\text { Informações gerais para } \\
\text { acompanhamento de programas, } \\
\text { ações, projetos e obras }\end{array}$ & 5 & 8 & 5 & 13 & 14 & 7 & 52 & $100 \%$ \\
\hline $\begin{array}{l}\text { Orientação sobre os procedimentos } \\
\text { para solicitação de informação }\end{array}$ & 5 & 8 & 5 & 13 & 14 & 7 & 52 & $100 \%$ \\
\hline $\begin{array}{c}\text { Disponibilização de "respostas e } \\
\text { perguntas" mais frequentes da } \\
\text { sociedade }\end{array}$ & 5 & 8 & 5 & 13 & 14 & 7 & 52 & $100 \%$ \\
\hline $\begin{array}{c}\text { Informação transparente, clara e } \\
\text { em linguagem de fácil } \\
\text { compreensão }\end{array}$ & 4 & 8 & 5 & 13 & 14 & 7 & 52 & $100 \%$ \\
\hline $\begin{array}{l}\text { Serviço de Informações ao Cidadão } \\
\text { (SIC) }\end{array}$ & 5 & 8 & 5 & 13 & 14 & 7 & 52 & $100 \%$ \\
\hline $\begin{array}{c}\text { Conteúdo acessível a pessoas com } \\
\text { deficiência }\end{array}$ & 5 & 8 & 5 & 13 & 14 & 7 & 52 & $100 \%$ \\
\hline
\end{tabular}

Fonte: Dados da pesquisa (2019)

A partir da Tabela 9 nota-se que apenas a ferramenta de pesquisa não foi disponibilizada por algumas prefeituras. É importante ressaltar a importância nos portais eletrônicos, dessa ferramenta como facilitadora no processo de coleta de dados não apenas 
para pesquisadores mas para qualquer cidadão interessado. Quanto as outras exigências, os municípios rondonienses atingiram grau máximo de adesão, com as prefeituras divulgando $100 \%$ de todos os indicadores das leis de acesso a informação. As regiões que não atenderam as obrigações legais na íntegra foram as Mesorregiões de Ji-Paraná e de Vilhena, que do total de municípios, apenas 4 e 3, respectivamente, não disponibilizaram a barra de pesquisa para os cidadãos.

Destaque para o município de Machadinho do Oeste que é o único do estado que disponibiliza o VLibras, que é o resultado de uma parceria entre o Ministério do Planejamento, Desenvolvimento e Gestão (MP), por meio da Secretaria de Tecnologia da Informação (STI) e a Universidade Federal da Paraíba (UFPB), a Suíte VLibras consiste em um conjunto de ferramentas computacionais de código aberto, responsável por traduzir conteúdos digitais (texto, áudio e vídeo) para a Língua Brasileira de Sinais - LIBRAS, tornando computadores, dispositivos móveis e plataformas Web acessíveis para pessoas surdas.

No estudo de Vieira, Bianchi e Kronbauer (2014), os indicadores que tiveram 100\% de transparência foram apenas 2: Informações Quanto à Estrutura Organizacional e a Divulgação de Endereços e Telefones. Já na pesquisa de Marques (2014), nenhum município conseguiu divulgar todas as informações básicas requeridas pelas leis de acesso a informação.

A transparência na gestão pública exige uma política específica. É um princípio a ser implementado de forma concertada e, portanto, exige capacidade da autoridade pública (Gomes Filho, 2005). Nestes termos, percebe-se que as autoridades públicas rondonienses possuem capacidade de oferecer transparência na gestão pública do estado à população. E ainda promovem a integração e respeito à comunidade de pessoas com deficiência, considerando que apresentou $100 \%$ de disponibilidade de acesso ao conteúdo para essas pessoas. Contudo, essa ação ainda é pouco adotada pelos gestores públicos. O trabalho de Silva (2013) mostra que esse item não foi disponibilizado por nenhum dos 56 municípios da amostra da pesquisa do Estado do Mato Grosso.

Para finalizar, o estudo, bem como outras pesquisas semelhantes foi constatado que houve maior transparência na adesão à Lei de Acesso à Informação que na divulgação dos planos orçamentários seguindo as exigências da Lei de Responsabilidade Fiscal. Como exemplo o trabalho de Marques (2014), seu estudo constatou uma baixa aderência média das prefeituras na divulgação de indicadores da LRF e uma aderência melhor na divulgação de indicadores da LAI. 


\section{CONSIDERAÇÕES FINAIS}

Este estudo teve como objetivo mostrar o nível de transparência dos municípios de Rondônia relacionado as exigências das leis de Responsabilidade Fiscal e de Acesso à Informação. Foram verificados os dados disponíveis no Portal da Transparência dos 52 municípios selecionados, a partir de indicadores pré-selecionados.

Os resultados mostraram que grande parte das informações solicitadas pelas leis estão sendo disponibilizadas de forma responsável pelas prefeituras, que apresentaram um alto grau de transparência na maioria dos requisitos. Somando-se a isso, os dados que ficaram disponíveis para os cidadãos são inteligíveis e coerentes, facilitando o acesso, o acompanhamento e o controle da sociedade.

Com a obtenção dos valores da estatística descritiva, notou-se que o Índice de Conformidade Geral Médio do Estado foi superior a 95\%, sendo ainda maior em relação à LRF (92,56\%), e um pouco abaixo se tratando da LAI (98,5\%). Essa característica se assemelha aos resultados obtidos por Vieira, Bianchi e Kronbauer (2014), em que o IC Médio da LAI também foi superior a IC LRF Médio e ao IC Geral Médio. Ressaltando que são semelhantes em desempenho, não em pontos percentuais.

Entre as seis mesorregiões estudadas, a região de Porto Velho apresentou menor nível de transparência, com IC Geral Médio de 94\%. O Portal da Transparência da região de Jaru mostrou o maior número de informações exigidas, assim obteve IC Geral Médio de 97,33\%. É importante ressaltar que não houve grande diferença nos resultados entre as regiões do Estado. Para ambos os índices de conformidade houve divulgação de pelo menos 90\%, chegando a $100 \%$ para alguns. Assim, todas as regiões apresentaram resultados que confirmam o cumprimento relativo a transparência pública.

Quanto à Lei de Responsabilidade Fiscal, os itens de Parecer Prévio de prestação de contas, as datas de audiências públicas quadrimestrais para avaliação das metas físcais e o incentivo à participação popular e audiências públicas no processo de elaboração e discussão de PPA, LDO e LOA, são as informações menos divulgadas pelas prefeituras. Em relação à LAI, o indicador menos atendido nos portais eletrônicos das prefeituras foi a disponibilização de ferramenta de pesquisa, todos os outros quesitos foram divulgados, confirmando que o Estado de Rondônia pode ser considerado referência no processo de transparência.

A Lei de Responsabilidade Fiscal e Lei de Acesso à Informação se referem a requisitos de cumprimento obrigatório, nesse sentido, é interessante destacar que, mesmo em 
municípios com menos de 5 mil habitantes, como Teixeirópolis e Castanheiras, que tem um poder econômico abaixo dos mais populosos, como Porto Velho e Ji-Paraná, sejam encontrados níveis de conformidade com cumprimento integral. Essa constatação mostra que a transparência não está relacionada a quantidade de pessoas vivendo em uma localidade ou sua capacidade econômica, (compromisso com o cumprimento legal e consequentemente estar livre de sansões que penalizam prefeituras que não atendem esses requisitos) e sim ter a consciência que um dos valores da democracia passa pelo compromisso honesto com os cidadãos de disponibilizar os atos de gestão, para que tenham maior participação na definição de políticas públicas.

Segundo a abordagem de Capella (2015, p.171) “A tecnologia é a causa fundamental das mudanças sociais, condicionando a percepção dos indivíduos, moldando a cultura, influenciando no funcionamento das instituições e alterando a própria história”. E os municípios do Estado de Rondônia entenderam a importância dessa ferramenta, visto que a maioria dos seus portais eletrônicos apresentam uma estrutura moderna e didática, que consequentemente facilitam na procura de informações especificas e extração de dados, assim o entendimento da realidade organizacional do Estado se torna mais simples e democrática.

Como foi exposto, o estudo revelou que o Estado de Rondônia tem um desempenho muito superior aos encontrados nos trabalhos citados neste artigo e que utilizaram a mesma metodologia relacionada ao cumprimento da LRF e LAI. Estudos deste tipo de outros estados da Região Norte podem indicar o grau de atendimento a essas leis e proporcionar comparações dentro da mesma Região.

\section{REFERÊNCIAS}

BRASIL. Presidência da República. Casa Civil. Lei Complementar Federal nº 101 de 4 de maio de 2000. Estabelece normas de finanças públicas voltadas para a responsabilidade fiscal e dá outras providências. Brasília, DF, 2000. Disponível em:

<http://www.planalto.gov.br/ccivil_03/leis/lcp/lcp101.htm>. Acesso em: 8 de out. de 2019.

BRASIL. Presidência da República. Casa Civil. Lei n. 12.527, de 18 de Novembro de 2011. Regula o acesso a informações previsto no inciso XXXIII do art. $5^{\circ}$, inciso II, do $\S 3^{\circ}$ do art. 37 e no $\S 2^{\circ}$ do art. 216 da Constituição Federal. Brasília, DF, 18 de novembro de 2011. Disponível em:<http://www.planalto.gov.br/ccivil_03/_ato2011 2014/2011/lei/112527.htm>. Acesso em: 8 de out. de 2019.

BRASIL. Presidência da República. Casa Civil. Lei Complementar $\mathbf{n}^{0}$ 131, de 27 de maio de 2009. Acrescenta dispositivos à Lei Complementar no 101, de 4 de maio de 2000, Brasília, DF, 2009. Disponível em: http://www.planalto.gov.br/ccivil_03/leis/lcp/lcp131.htm. Acesso em: 8 de out. de 2019. 
BROCCO, C.; GRANDO, T.; MARTINS, V.Q.; JUNIOR, A.C.B; CORRÊA, S.; Transparência da gestão pública municipal: fatores explicativos do nível de transparência dos municípios de médio e grande porte do rio grande do sul. Revista Ambiente Contábil - ISSN 2176-9036 - UFRN - Natal-RN. v. 10. n. 1, p. 139 - 159, jan./jun. 2018.

CONTE, Nelton Carlos; SANTOS, Sandra Regina Toledo dos. Planejamento, orçamento e contabilidade aplicada ao setor público. Passo Fundo: Universidade de Passo Fundo, 2014.

CAPELLA, A.C.N. Gestão Pública e Tecnologia da Informação: Um panorama contemporâneo. Governo Na Web: reflexões teóricas e práticas, volume 2. - 1. ed. Campinas, SP: Editora Alínea, 2015.

GOMES FILHO, A.B. O desafio de implementar uma gestão pública transparente. In: CONGRESO INTERNACIONAL DEL CLAD SOBRE LA REFORMA DEL ESTADO Y DE LA ADMINISTRACIÓN PÚBLICA, X, Santia15 a 25.

IBGE. Instituto Brasileiro de Geografia e Estatística. Disponível em:< https://cidades.ibge.gov.br/> Acesso em: 5 de out. de 2019.

MARQUES, S.B.S da S. Transparência nos pequenos municípios do Rio Grande do Sul: Um estudo sobre a divulgação de indicadores da LRF e da LAI. Universidade do Rio dos Sinos, Programa de Pós-Graduação em Ciências Contábeis, São Leopoldo, RS, 2014.

SILVA, A.L.; Evidenciação de Informações em Páginas Web de Prefeituras Municipais Mato-Grossenses: Uma Análise de Aderência a Lei de Responsabilidade Fiscal e A Lei de Acesso à Informação. Dissertação (mestrado) - Universidade do Rio do Sinos, Programa de Pós-Graduação em Ciências Contábeis, 2013.

SILVA, L. V. B.; Lei de acesso à informação e controle social: um estudo do nível de transparência dos órgãos do Poder Executivo do Estado de Pernambuco. 2017. 112 folhas: Dissertação (Mestrado em Ciências Contábeis) - Universidade Federal de Pernambuco. CCSA, 2017.

TCU. Tribunal de Contas da União. Governança Pública: referencial básico de governança aplicável a órgãos e entidades da administração pública e ações indutoras da melhoria. Brasília: TCU, 2014.

VIEIRA, E.E.M.; BIANCHI, M.; KRONBAUER, C.A.; Análise do Grau de Aderência à Lei de Responsabilidade Fiscal e à Lei de Acesso à Informação nos Municípios do Estado do Rio Grande do Sul com Mais de 50 Mil Habitantes. Desenvolvimento em Questão. Editora Unijuí, p. 131-163. ano 15 n. 41 out./dez. 2017. 